\title{
Medios escolares, escenarios para formar sujetos políticos en la escuela
}

\section{School media, scenarios to form political subjects in school}

\begin{abstract}
Juan Carlos Ceballos Sepúlveda es Profesor Titular de la Universidad Pontificia Bolivariana (Colombia) (juan.ceballos@upb.edu.co) (D) (http://orcid.org/0000-0002-1627-137X)
\end{abstract}

Julián Darío Forero Sandoval es Profesor Titular, Universidad Pontificia Bolivariana (Colombia) (julian.forero@upb.edu.co) (D) (https://orcid.org/0000-0002-5283-8425)

Alfredo Álvarez Orozco es Profesor Asociado de la Universidad Pontificia Bolivariana (Colombia) (alfredo.alvarez@upb.edu.co) (iD) (https://orcid.org/0000-0003-0271-0199)

Recibido: 2019-01-29 / Revisado: 2019-04-28 / Aceptado: 2019-05-17 / Publicado: 2019-07-01

\section{Resumen}

La investigación busca aportar a la formación de sujetos políticos desde la condición de estudiantes y participantes activos en la producción de medios de comunicación escolar. Se trata de un estudio cualitativo que indaga sobre alternativas de educación ciudadana, con jóvenes de educación secundaria que asumen el rol de productores de medios escolares. Toda la propuesta se fundamentó epistemológicamente en los conceptos: comunicación/educación, medios escolares y sujeto político. Desde esta perspectiva, el proyecto se materializó en tres ciudades de Colombia (Medellín, Montería y Bucaramanga) y seis instituciones educativas de carácter oficial y privado, con una ruta metodológica orientada por un estudio etnográfico que facilitó observar cómo se producen los medios escolares a partir de la triangulación de información recolectada en entrevistas y grupos focales, y sistematizada en el programa NVivo. Esta metodología permitió comprender, desde los estudiantes como sujetos de estudio, los procesos de formación política con el manejo de la información y los contenidos de los medios escolares de las instituciones públicas y privadas. No obstante, se evidenció una concepción común de lo político que supera la idea de representatividad para ser dimensionada como el trabajar por el bienestar de todos y la construcción de sociedad.

Descriptores: Medios escolares, sujeto político, ciudadanía, política, colegios, educación.

\begin{abstract}
This research intends to contribute to the formation of political subject as students and active participants in the production of school communication media. It refers to a qualitative study which inquiries about the alternatives for the citizen education, with high school students who assume the roles of produc-
\end{abstract}

Forma sugerida de citar: Ceballos Sepúlveda, J. C., Forero Sandoval, J., \& Álvarez Orozco, A. (2019). Medios escolares, escenarios para formar sujetos políticos en la escuela. Alteridad, 14(2), 243-255. https://doi.org/10.17163/alt.v14n2.2019.08 
ers of scholar media. The entirety of the proposal is epistemologically based on the concepts: communication/education, school media and political subject. In this perspective, the project materialized in three cities of Colombia (Medellín, Monteria and Bucaramanga) and six public and private educative institutions, with a methodological route guided by an ethnographic study that facilitated observing how school media are produced drawn from the triangulation of collected information from focus groups and interviews, and then digitalized in the NVivo software. This methodol-

\section{Introducción y estado de la cuestión}

Los medios de comunicación escolar generan diversas tensiones en la escuela. Freinet (1977) introdujo la imprenta en el aula, con el fin de favorecer el relato basado en la propia vida de los estudiantes. Luego, en América Latina, la mayoría de estos proyectos siguen enfoques instrumentales, divulgativos y centrados en los adultos (maestros) (Huergo, \& Fernández, 2000), (Kaplún, 2010) o desarticulados de proyectos institucionales como lo plantean (Rodríguez, 2004) y (Valderrama, 2007) que distan de lo planteado por el educador francés en la segunda década del siglo XX.

Con la incorporación de las tecnologías, las discusiones se centran en la apropiación o negación de la cultura digital, ya sea para ampliar el ejercicio del Derecho a la comunicación (Bacher, 2009) o seguir con prácticas tradicionales de escritura. El reto para la escuela está en favorecer que los estudiantes apropien otros lenguajes, además de la escritura, para producir contenidos, memorias y realidades y generar procesos de intercambio simbólico y cultural (Romero, 2011).

Tres grupos de investigación de la Universidad Pontificia Bolivariana de Colombia, ${ }^{1}$ UPB, ejecutaron el proyecto "Medios escolares como espacios de formación del sujeto político en instituciones educativas de Medellín, Montería y Bucaramanga", con el propósito de ogy allowed furthermore, comprehending from the students, as subjects of study, the processes of political formation with the management of information and the content of the school media in public and private institutions. Nonetheless, a common conception of the political was evidenced, and it overcomes the idea of representativeness to become dimensioned as the construction of society and the work in aims of everyone's wellbeing.

Keywords: School media, political subjects, citizenship, politics, schools, education.

indagar si los medios escolares sirven de espacio para la formación del sujeto político, en los que expresan las maneras de ver sus mundos (Valderrama, 2010), atravesada por la cultura experiencial (Pérez, 1998), la apropiación de la palabra para narrar esos mundos (Freire, 1985) y en donde pueda desarrollar la consciencia crítica, la capacidad de disenso, la autonomía, el liderazgo y el empoderamiento (Rojas, \& Arboleda, 2014), algunas de las características que identifican al sujeto político.

Se aplicó una metodología cualitativa de tipo etnográfico, para observar el proceso de producción de los medios escolares en instituciones educativas, apoyadas con entrevistas y grupos focales a estudiantes y profesores.

La investigación está centrada en el proceso de producción del medio escolar y el cambio de rol del estudiante, quien pasa de ser un "mero receptor" a productor de sentidos (Martín Barbero, 1998); la participación en estas experiencias permite otras opciones culturales: "brindarles la posibilidad de conocer, ver, sentir, experimentar con el objetivo de intervenir y transformar" (Gamarnik, 2011, p. 13); esto es, pasar del receptor al actor social y productor de sentidos.

El estudio está soportado en tres conceptos: la comunicación/educación, los medios de comunicación escolar y el sujeto político. La base inicial de esta relación es la educación problematizadora (Freire, 1985) por su carácter reflexivo y como acto permanente de descubrimiento de 
la realidad (p. 88); una educación que supera la transmisión y acumulación de información, y desarrolla en los estudiantes el pensamiento crítico, una lectura de su experiencia de vida relacionada con el contexto educativo y social, y que luego narra apropiando diferentes lenguajes de la comunicación (Perceval, \& Tejedor, 2008) que la constituye en un aprendizaje significativo (Aparici, \& García, 2017), similares a los rasgos que identifican el sujeto político.

La relación comunicación y educación está marcada por dos perspectivas: para Barbas (2012), la educomunicación es "proceso, movimiento, flujo de significados, acción creativa y re-creativa, construcción-deconstrucciónreconstrucción permanente de la realidad" (pp. 166-167) y Huergo (2001) quien sostiene que esa relación comunicación/educación (con la barra) es una articulación basada en la "formación de sujetos (objeto de la educación) y producción de sentidos (objeto de la comunicación)" (p. 28).

El medio escolar se asume desde dos conceptos: el primero, como dispositivos para visibilizar experiencias de aula y para que los integrantes de la comunidad educativa produzcan "contenidos, memorias y realidades que son compartidas con su entorno en un proceso de intercambio simbólico y cultural" (Romero, 2011, p. 48); y como espacios para contar "las historias de su vida, en un acto legítimo de comunicación, no sólo a sus compañeros, sino a los habitantes de su contexto"(p. 50); el segundo, Ceballos y Marín (2017) indican que los medios escolares son espacios de comunicación, educación y cultura, producidos de forma colectiva por la comunidad educativa, para

Generar reflexiones y conversaciones a partir de los temas publicados, de manera que favorezca procesos de diálogo y discusión entre los destinatarios de estos contenidos y (...) llevarlos a que compartan estos mensajes con otros destinatarios (p. 58).
El concepto de sujeto político se basa en Fernández quien comparte algunas de sus características: "democrático, con sentido de comunidad, en capacidad de desarrollar una opinión personal y establecerse como receptor activo, generador y transmisor de conocimiento en su cotidianidad" (2015, p. 89). A lo que Rojas y Arboleda (2014) complementan: respeto a la diferencia, aceptación de otras formas de pensar, actuar y accionar en mundo simbólico y real. A esto se suma lo que Ruiz y Prada (2012) indican que el hecho de contar su vida, construir relatos, describir los propios contextos, permite al sujeto comprometerse con la acción y con los procesos de transformación, ahí reside el sentido de la subjetividad política y el ejercicio de la crítica (p. 51), por eso, como señala Kriger (2010) se llega a ser sujeto político cuando existe la intención de cambiar el mundo del que hace parte. Estos aspectos aparecen en los medios escolares, cuando son entendidos como un espacio o proceso de producción de unos contenidos, donde los estudiantes pueden reconocerse en la diferencia, debatir sus puntos de vista, mostrar su liderazgo, su capacidad de llegar a acuerdo y de comunicar sus ideas que den cuenta de lo que viven en la escuela y en su contexto social.

\section{Material y métodos}

La investigación desarrollada fue cualitativa. Tuvo un interés por preguntar, interpretar y relacionar lo observado: "enfatiza en la comprensión y la interpretación desde los sujetos y su proceso de significación en contextos educativos concretos, con sus creencias, intenciones y motivaciones" (Reynaga, 1998, p. 126).

Para captar los conocimientos propios de estudiantes y profesores que integran los medios escolares, se trabajó la entrevista etnográfica (Guber, 2001), como ejercicio reflexivo entre investigador, estudiantes y maestros: "es una relación social de manera que los datos que provee 
el entrevistado son la realidad que éste construye con el entrevistado en el encuentro" (p. 77).

Los grupos focales, según Reguillo (1998), aportan el carácter reflexivo del instrumento:

Al ponerse en evidencia lo que de colectivo tiene la experiencia individual, los sujetos entran en una dinámica de negociación de significados tanto con los otros sujetos como consigo mismos (p. 35).

El proceso de selección de las instituciones educativas en cada ciudad (Medellín, Bucaramanga, Montería), se hizo con los siguientes criterios: cinco o más años de publicación del medio escolar; equipo de trabajo conformado por estudiantes y orientado por un docente; reuniones periódicas (semanales o quincenales), dentro de una institución educativa pública y una privada, para tener diferentes puntos de referencia. En total fueron 6 instituciones educativas, dos por cada ciudad. El trabajo de campo de adelantó en segundo semestre de 2017, entre agosto y noviembre, el segundo periodo de programación académicas en colegios de educación secundaria en Colombia.

\section{Análisis de resultados}

Los datos obtenidos son cualitativos: conceptos e ideas que surgen a partir de las entrevistas o los grupos focales. Para este artículo se retoman las preguntas planteadas a los actores sobre dos conceptos: medio escolar y el sujeto político. Siguiendo a Angrosino (2012), las categorías éticas, resultado de un levantamiento teórico (ya expuesto), adquieren otras significaciones a par- tir los comentarios que hacen los estudiantes y maestros consultados, pasando así a una dimensión "émica" (pp. 99-100). A partir del registro de las entrevistas y grupos focales, se concretaron los conceptos, aplicando el software Nvivo.

A continuación, se hará una breve reseña de las Instituciones Educativas (I.E) y se expondrán los resultados obtenidos con su respectivo análisis, teniendo presente la pregunta de investigación: ¿Qué aporta a la formación del estudiante, como sujeto político, la participación en la producción de medios escolares de instituciones educativas públicas y privadas?

\subsection{Medellín}

Institución Educativa Pública (I.E. Pública): fundada en 1970, cuenta con cinco mil estudiantes en los niveles Primaria, Secundaria, Media Técnica y Media Académica. El medio escolar es un periódico fundado en 1979, tiene periodicidad anual, con 61 ediciones publicadas hasta 2017. Es coordinado por un comunicador y profesor que hace parte del Departamento de Lengua Castellana. El equipo de redacción estaba integrado por diez estudiantes.

Institución Educativa Privada (I.E. Privada): fundada en 1957 y su modalidad es académica, impartida a hombres y mujeres desde el preescolar hasta la básica secundaria y media. Las experiencias de los medios escolares en la I.E. datan de hace más de diez años, con periódicos, programas de TV o emisoras escolares. Para este caso se tuvo en cuenta la emisora escolar, coordinada por un profesor del área de Lengua Castellana y tenía como apoyo un grupo de seis estudiantes que emitían un programa semanal. 
Tabla 1. Resultados entrevistas estudiantes y profesores de Medellín sobre medios escolares

\begin{tabular}{|c|c|c|c|c|}
\hline Pregunta & \multicolumn{2}{|l|}{ Actor } & Concepto & Idea \\
\hline \multirow{6}{*}{$\begin{array}{l}\text { ¿Qué es un } \\
\text { medio escolar? }\end{array}$} & $\begin{array}{l}\text { Estudiante } \\
\text { Pública }\end{array}$ & I.E. & $\begin{array}{l}\text { Un medio escolar es como, en este caso el perió- } \\
\text { dico, que viene siendo parte de toda la comunidad } \\
\text { educativa y que los incluye a todas las personas } \\
\text { del colegio para transmitir información, transmi- } \\
\text { tir pensamientos, ideas, pues una nueva forma } \\
\text { como de aprendizaje. }\end{array}$ & $\begin{array}{l}\text { - Periódico } \\
\text { - Comunidad educativa } \\
\text { - Trasmisión } \\
\text { - Pensamientos } \\
\text { - Aprendizajes }\end{array}$ \\
\hline & $\begin{array}{l}\text { Estudiante } \\
\text { Pública }\end{array}$ & I.E. & $\begin{array}{l}\text { Un medio escolar es un proceso, una organiza- } \\
\text { ción de unas ideas, unos conocimientos, unos } \\
\text { conceptos que son organizados para transmitirlos } \\
\text { a los estudiantes del colegio, a los docentes, a los } \\
\text { directivos. }\end{array}$ & $\begin{array}{l}\text { - Proceso } \\
\text { - Reunión de ideas } \\
\text { - Conocimientos } \\
\text { - Conceptos } \\
\text { - Transmisión } \\
\text { - Comunidad educativa }\end{array}$ \\
\hline & $\begin{array}{l}\text { Estudiante } \\
\text { Privada }\end{array}$ & I.E. & $\begin{array}{l}\text { Método que estudiantes y profesores utilizan para } \\
\text { informarse sobre las cosas nuevas que pasan en } \\
\text { el colegio. }\end{array}$ & $\begin{array}{l}\text { - Método para informar } \\
\text { - Información de } \\
\text { actualidad }\end{array}$ \\
\hline & $\begin{array}{l}\text { Estudiante } \\
\text { Privada }\end{array}$ & I.E. & $\begin{array}{l}\text { El medio estudiantil lo que hace es dar informa- } \\
\text { ción neutra, o sea, aunque seamos estudiantes y } \\
\text { nos duela decir que el profesor tenía razón, tene- } \\
\text { mos que estar del lado del profesor. }\end{array}$ & $\begin{array}{l}\text { - Información neutra } \\
\text { - Profesor }\end{array}$ \\
\hline & $\begin{array}{l}\text { Profesor } \\
\text { Pública }\end{array}$ & I.E. & $\begin{array}{l}\text { Es un canal de comunicación y discusión de cier- } \\
\text { tas problemáticas que se ven en el colegio, es } \\
\text { (...) como ese espacio donde ellos pueden dar } \\
\text { sus propias opiniones sin que sean coartados o } \\
\text { presionados (...) es un espacio para discutir y } \\
\text { debatir ciertas problemáticas, no solamente de } \\
\text { la institución, sino también de la ciudad (...) los } \\
\text { muchachos son los que escriben en gran mayoría. }\end{array}$ & $\begin{array}{l}\text { - Canal de comunicación } \\
\text { y discusión } \\
\text { - Espacio para opinar sin } \\
\text { censura } \\
\text { - Debatir temas de la } \\
\text { institución y la ciudad }\end{array}$ \\
\hline & $\begin{array}{l}\text { Profesor } \\
\text { Privada }\end{array}$ & I.E. & $\begin{array}{l}\text { El medio escolar lleva información institucional y } \\
\text { de interés de los estudiantes. Es un vehículo para } \\
\text { expresar (...) en principio es para la libre expre- } \\
\text { sión, pero debe haber una leve censura, porque } \\
\text { podrían publicar cosas que no se acepten. }\end{array}$ & $\begin{array}{l}\text { - Información institucional } \\
\text { - Vehículo de expresión } \\
\text { - Libre expresión } \\
\text { - Censura leve } \\
\text { - Conservar línea } \\
\text { institucional }\end{array}$ \\
\hline
\end{tabular}

A partir de estos comentarios, se aprecian algunas diferencias en las ideas de un medio escolar, en un contexto público y uno privado. En el primero, se trata de un medio con un enfoque escolar (producido por estudiantes); en el que circulan además de información, conocimientos, pensamientos e ideas lo que da un carácter diferente a los contenidos, para ser compartidos en la comunidad educativa. Un aporte clave es asociar el medio como un proceso y no como resultado o producto final (Mujica, 2001), un estímulo a la expresión de los alumnos. Se destaca que el medio escolar permite expresar pensamientos e ideas que son conocidos por los otros al momento de publicarse los contenidos; es una construcción colectiva y producto social como lo señala Kaplún (1998). Diferente a los conceptos en la I.E. privada, porque en esta sur- 
gen algunas expresiones asociadas a los canales (parlantes, por ejemplo), a la divulgación de información institucional de aquello "que pasa en el colegio" y, sobre todo, la idea de transmitir información por "tecnologías neutras" (Saintout, 2003), por tanto, sin comprometer unas ideas o pensamientos críticos, supeditada a la aprobación del profesor.

Desde las perspectivas de los docentes, en la I.E. pública se percibe una idea de posicionar al estudiante como autor de sus escritos, con posibilidad de expresar sus opiniones ya sea de la institución o de la ciudad, sin ánimo de ser coartados: "las ideas circulan, se intercambian y confrontan"
(Henao, 2012, p. 133). En la I.E. privada es contradictoria: por un lado, reconoce que es un vehículo de libre expresión, pero al mismo tiempo señala que debe tener cierto nivel de censura.

En un ambiente de confianza y compromiso para expresar ideas, opiniones y elaborar contenidos propios, puede existir la consciencia de publicar contenidos con un carácter público, para impactar a la comunidad educativa, "escribir para ser leídos” (Freinet, 1983). Contrario, si los estudiantes están supeditados a una censura, así sea leve, para expresar sus ideas, sus temas u opiniones, se limita su campo de participación y de incidencia en estos espacios.

Tabla 2. Resultados entrevistas estudiantes y profesores Medellín sobre el ser político

\begin{tabular}{|c|c|c|c|}
\hline Pregunta & Actor & Concepto & Idea \\
\hline \multirow{6}{*}{$\begin{array}{l}\text { ¿Qué es } \\
\text { el ser } \\
\text { político? }\end{array}$} & $\begin{array}{l}\text { Estudiante } \\
\text { I.E. Pública }\end{array}$ & $\begin{array}{l}\text { El ser político es la capacidad de una persona de crear } \\
\text { consciencia de su medio, y aportar ideas para trans- } \\
\text { formar (...) es tener sentido de pertenencia, esa capa- } \\
\text { cidad para transmitir buenas ideas. }\end{array}$ & $\begin{array}{l}\text { - } \text { Crear consciencia } \\
\text { - Ideas para transformar } \\
\text { - Sentido de pertenencia } \\
\text { - Capacidad de transmitir } \\
\text { buenas ideas }\end{array}$ \\
\hline & $\begin{array}{l}\text { Estudiante } \\
\text { I.E. Pública }\end{array}$ & $\begin{array}{l}\text { Un ser político tiene que ser alguien responsable, que } \\
\text { sea crítico y que tenga como unas capacidades de lide- } \\
\text { rar, de saber resolver situaciones. }\end{array}$ & $\begin{array}{l}\text { - Responsable } \\
\text { - Crítico } \\
\text { - Liderazgo } \\
\text { - Resolver situaciones }\end{array}$ \\
\hline & $\begin{array}{l}\text { Estudiante } \\
\text { I.E. Privada }\end{array}$ & $\begin{array}{l}\text { Es una persona que expresa y siente lo que quiere, (...) } \\
\text { quiere sacar adelante a su país, a su ciudad, a su mu- } \\
\text { nicipio, a su idea y a su pensamiento. }\end{array}$ & $\begin{array}{l}\text { - Capacidad de expresión } \\
\text { - Compromiso con la } \\
\text { sociedad }\end{array}$ \\
\hline & $\begin{array}{l}\text { Estudiante } \\
\text { I.E. Privada }\end{array}$ & $\begin{array}{l}\text { Es ser una persona íntegra que sabe de muchas cosas, } \\
\text { de muchas opiniones que puede no compartir, pero que } \\
\text { respeta, no debería ser un corrupto como cuando pen- } \\
\text { samos en la política colombiana, (...) implementa su } \\
\text { opiniones de una forma respetuosa con todos. }\end{array}$ & $\begin{array}{l}\text { - } \text { Conocimientos } \\
\text { - Opinión } \\
\text { - Persona integra } \\
\text { - } \text { Respeto }\end{array}$ \\
\hline & $\begin{array}{l}\text { Profesor I.E. } \\
\text { Pública }\end{array}$ & $\begin{array}{l}\text { Una persona que participa en los diversos escenarios } \\
\text { de la ciudad y del país (...) una persona que aporta con } \\
\text { un espíritu crítico a que su barrio sea mejor. }\end{array}$ & $\begin{array}{l}\text { - Participa } \\
\text { - Aporta } \\
\text { - Espíritu crítico }\end{array}$ \\
\hline & $\begin{array}{l}\text { Profesor } \\
\text { I.E.Privada }\end{array}$ & $\begin{array}{l}\text { Ser político me parece que no está divorciado con una } \\
\text { línea de pensamiento (...) es estar metido en la discu- } \\
\text { sión política del país. }\end{array}$ & $\begin{array}{l}\text { - Línea de pensamiento } \\
\text { (política) } \\
\text { - Afiliación política } \\
\text { - Participante en discusión } \\
\text { política }\end{array}$ \\
\hline
\end{tabular}


Entre los estudiantes de ambas instituciones emergen algunas características, relacionadas con el "ser político", asociadas a quienes trabajan por el bien común: aquellas que crean consciencia, son responsables, tienen sentido de pertenencia y aportan sus conocimientos a una sociedad, tienen capacidad de liderazgo y de escucha, buscan hacer el bien y plantean soluciones. Algunos lo relacionan con la corrupción. Las respuestas indican que los estudiantes consideran importante tener consciencia del ser político, conducente a la construcción de una sociedad y sentirse parte de un "nosotros" (Nussbaum, 2014).

Los profesores tienen ideas más básicas del ser político. Para el de la institución es quien participa en espacios cercanos donde pueda tener injerencia directa, como el barrio y no solo ejerciendo el derecho al voto. El de la institución privada considera que es aquel que tiene una ideología o una filiación a un partido político y su participación está enmarcada en la discusión política, relacionada con la política tradicional.

Según lo anterior, vale la pena considerar algunas ideas compartidas acerca de sí el hecho de integrar y participar en medios escolares aportan a la formación del sujeto político. Para ello, se preguntó a estudiantes y profesores: La participación en el medio escolar ¿Qué aporta a la formación del ser político?

Al respecto, los estudiantes de la institución educativa pública respondieron:

La capacidad de liderazgo, aprender a aceptar las ideas de las otras personas (...) como ser humano me debo de considerar dentro de una sociedad; mis ideas no pueden ser únicas, debo aprender a trabajar en comunidad. (Estudiante 1)

... desde los temas tratados se puede aprender bastante de ellos y tener un criterio propio y proponer una solución y querer un bien para la sociedad. (Estudiante 2).

Por su parte, en la Institución Educativa privada, compartieron:
Más que todo habilidades sociales, nosotros estudiamos en un colegio mixto que nos da grandes ventajas en el campo social; la radio nos ha formado como ciudadanos, que yo siento muy positivos, porque, aunque escuchamos y tenemos nuestras opiniones claras, estamos informados. (Estudiante 1).

Aporta a mi personalidad (...) es aceptar que el otro también tiene personalidad, y también va hacer otras cosas. (Estudiante 2)

Los estudiantes valoran que participar en un medio escolar, como espacio y proceso no como producto, les da capacidad de palabra y reflexión crítica, a lo largo del proceso de producción, materializado en las reuniones y en el encuentro entre los pares (estudiantes y con los maestros), lugar donde aprende a valorar el respeto por la diferencia. Además, potencia el liderazgo, adquirir criterio propio, aprender de los temas y plantear soluciones a los problemas. Los jóvenes necesitan voz, ser vistos y tenidos en cuenta "es el derecho a existir socialmente" (Martínez, 2014).

Los profesores indicaron:

El periódico es el medio institucional del colegio (...) a medida que vamos haciendo las discusiones y, entre ellos mismos se van dando cuenta $(. .$.$) de que hay unas normas,$ unos parámetros, una responsabilidad social, de que hay una ética como comunicadores (...) como todos ellos son distintos, les toca también escuchar otras voces y tienen que escuchar también qué piensa el otro. (Profesor, Institución Educativa pública)

He procurado que ellos sean objetivos, (...) en el sentido de que al que entrevistan, si no están de acuerdo con él, no lo van a deslegitimar. Si están desacuerdos, ese desacuerdo inicial que tienen lo que he procurado es que no vicie el artículo. (Profesor Institución Educativa privada)

De acuerdo con lo expuesto por los profesores, la participación en un medio escolar implica hacer el reconocimiento de unas normas 
$\mathrm{y}$, ante todo, el reconocimiento de la voz del otro como diferente. Por eso, requiere que el medio escolar sea considerado como un proceso, más que un producto que sirve de canal o instrumento restringido a divulgar información institucional; en términos de Freire (2008) es "una experiencia gnoseológica" (p. 50), en este caso, experiencia de construcción de conocimiento y formación del sujeto político.

\subsection{Montería}

Institución Educativa Pública (I.E. Pública): fundada en 1970, tiene una cobertura de 2000 estudiantes para todos los niveles de la educación básica primaria y secundaria. Cuenta con 82 docentes, cuatro directivos y seis administrativos. El medio escolar es un programa de televisión que tiene una periodicidad mensual, años años de trabajo e integrado por un grupo de trece estudiantes que se distribuyen las funciones de preproducción y producción audiovisual, coordinados por el profesor del área de Ciencias Sociales.

Institución Educativa Privada (I.E. Privada): fundada en 1958, es un colegio administrado por una comunidad cristiana que también ofrece todos los grados de formación básica, desde el prescolar hasta el bachillerato. El medio escolar es una revista impresa que se publica anualmente, con una trayectoria de seis años y es coordinada por un comunicador social con el apoyo de catorce estudiantes.

Tabla 3. Resultados entrevistas estudiantes y profesores Montería sobre el medio escolar

\begin{tabular}{|c|c|c|c|}
\hline Pregunta & Actor & Concepto & Idea \\
\hline \multirow{4}{*}{$\begin{array}{l}\text { ¿Qué es un } \\
\text { medio escolar? }\end{array}$} & $\begin{array}{l}\text { Estudiante I.E. } \\
\text { Pública }\end{array}$ & $\begin{array}{l}\text { Se define como un sistema diseñado para la co- } \\
\text { municación y la información de la población esco- } \\
\text { lar; espacio en donde se usan diferentes métodos } \\
\text { que logren atraer al receptor, en este caso, a los } \\
\text { estudiantes. }\end{array}$ & $\begin{array}{l}\text { - Sistema para la comuni- } \\
\text { cación y la información } \\
\text { - Población escolar } \\
\text { - Receptor }\end{array}$ \\
\hline & $\begin{array}{l}\text { Estudiante I.E. } \\
\text { Privada }\end{array}$ & $\begin{array}{l}\text { Espacio que brinda una institución para informar } \\
\text { sobre distintos hechos, novedades y actividades } \\
\text { relacionadas con ella. }\end{array}$ & - Espacio para informar \\
\hline & $\begin{array}{l}\text { Profesor } \\
\text { I.E. Pública }\end{array}$ & $\begin{array}{l}\text { Es un medio que visibiliza mucho a la comunidad } \\
\text { y empodera a los chicos que lo hacen y los motiva } \\
\text { a lograr cosas más lejanas. }\end{array}$ & $\begin{array}{l}\text { - Medios para visibilizar. } \\
\text { - Empoderar }\end{array}$ \\
\hline & $\begin{array}{l}\text { Profesor } \\
\text { I.E. Privada }\end{array}$ & $\begin{array}{l}\text { Es un medio que sirve para poner en contexto la } \\
\text { realidad institucional ante los públicos objetivos } \\
\text { que tiene la organización y para generar interés } \\
\text { en el medio externo. También para facilitar los } \\
\text { procesos de comunicación interna y para aportar } \\
\text { conocimiento a los estudiantes sobre redacción, } \\
\text { investigación, ortografía, entre otros. }\end{array}$ & $\begin{array}{l}\text { - Poner en contexto } \\
\text { - Públicos objetivos } \\
\text { - Procesos de comunica- } \\
\text { ción interna } \\
\text { - Aportar conocimiento }\end{array}$ \\
\hline
\end{tabular}

Se observa una divergencia en la concepción de lo que es y significa un medio escolar para los entrevistados de las instituciones educativas pública y privada. En la primera, la definición del concepto es más amplia: responde a los intereses de lo institucional e involucra a las comunidades de la ciudad que tienen acceso al programa de televisión. Por su parte, en el colegio privado, la prioridad está en informar sobre los temas de interés institucional, enfocados en los destinatarios internos y externos de la revista impresa. También, el medio escolar es una estrategia curricular que apoya y fomenta habilidades y competencias de escritura e investigación.

En general, en las dos instituciones se aprecia a los medios masivos, como un referente a tener en cuenta, no tanto por los contenidos donde hay un distanciamiento de la agenda informativa, sino en la forma de presentar los temas. Así, los estudiantes de ambas institucio- 
nes asumen como propio el medio escolar y lo definen como una manera particular de dar a conocer la vida cotidiana.

Las posturas de los responsables de los medios de ambas instituciones mantienen cierta coherencia con lo expresado por los estudiantes, porque permite la iniciativa para proponer los temas, principio formativo que, para Ruiz (2008) orienta hacia la educación "de sujetos políticos, ciudadanos participativos y propositivos" (p. 124). Sobre el sujeto político:

\section{Tabla 4. Resultados entrevistas estudiantes y profesores de Montería sobre el ser político}

\begin{tabular}{|c|c|c|c|c|}
\hline Pregunta & Actor & & Concepto & Idea \\
\hline \multirow{4}{*}{$\begin{array}{l}\text { ¿Usted se con- } \\
\text { sidera un ser } \\
\text { político? }\end{array}$} & $\begin{array}{l}\text { Estudiante } \\
\text { Pública }\end{array}$ & I.E. & $\begin{array}{l}\text { Yo si... porque, digamos en el caso de mi salón, yo soy } \\
\text { la monitora, entonces yo soy la encargada de velar por } \\
\text { lo que ellos me piden y cuando tenemos alguna nece- } \\
\text { sidad yo soy la que velo por ellos y pues esa es como } \\
\text { una forma política de estar mejor con lo que queremos. }\end{array}$ & $\begin{array}{l}\text { - Velar por los demás } \\
\text { - Estar mejor }\end{array}$ \\
\hline & $\begin{array}{l}\text { Estudiante } \\
\text { Pública }\end{array}$ & I.E. & $\begin{array}{l}\text { Pero no es solo que, si la persona te pide a ti que tú } \\
\text { eres un representante, alguien que se ve mayor ante } \\
\text { ellos, no es que, si te piden algo, entonces tú enseguida } \\
\text { lo vas a hacer. Primero tienes que analizar y ver si eso } \\
\text { que ellos piden va a ser para beneficio o para un mal } \\
\text { de la sociedad. }\end{array}$ & $\begin{array}{l}\text { - Representar a } \\
\text { alguien } \\
\text { - El beneficio social }\end{array}$ \\
\hline & $\begin{array}{l}\text { Estudiante } \\
\text { Privada }\end{array}$ & I.E. & $\begin{array}{l}\text { Si soy política cuando sé dar mi opinión, y entiendo la } \\
\text { opinión de los demás... soy político cuando entiendo } \\
\text { que el mundo no solo piensa como uno, sino que cada } \\
\text { uno tiene una opinión diferente; si hay } 40 \text { personas hay } \\
40 \text { mundos diferentes. Ser político es saber llevar esas } \\
40 \text { opiniones bajo un mismo camino a pesar de que no } \\
\text { todas piensen igual, eso es ser política. }\end{array}$ & $\begin{array}{l}\text { - Diversidad de } \\
\text { opiniones } \\
\text { - Diferentes } \\
\text { perspectivas }\end{array}$ \\
\hline & $\begin{array}{l}\text { Estudiante } \\
\text { Privada }\end{array}$ & I.E. & $\begin{array}{l}\text { Saber que en una sociedad siempre van a existir unos } \\
\text { choques, unos contrastes y uno va a saber entender } \\
\text { esas cosas, porque somos seres sociales que pode- } \\
\text { mos relacionarnos con los otros y podemos entender- } \\
\text { nos a sí mismos. }\end{array}$ & $\begin{array}{l}\text { - Diferencia } \\
\text { - Seres sociales } \\
\text { - Entendimiento } \\
\text { mutuo. }\end{array}$ \\
\hline \multirow{2}{*}{$\begin{array}{l}\text { ¿De qué mane- } \\
\text { ra los conteni- } \\
\text { dos publicados } \\
\text { en el medio } \\
\text { escolar aportan } \\
\text { a la formación } \\
\text { política de la } \\
\text { comunidad } \\
\text { educativa? }\end{array}$} & $\begin{array}{l}\text { Profesor } \\
\text { Pública }\end{array}$ & I.E. & $\begin{array}{l}\text { Desde todo punto, de alguna manera, lo que muestran } \\
\text { es su sentir político, pero ellos han aprendido a que no } \\
\text { debemos imponer: debemos compartir, para bien. } \\
\text { Es indudable que se forman seres con pensamiento } \\
\text { político, la dinámica les hace comprender que, como } \\
\text { actores sociales, somos políticos (a diferencia de la } \\
\text { politiquería), que eso es determinante para construir } \\
\text { sociedad. }\end{array}$ & $\begin{array}{l}\text { - El Sentir político } \\
\text { - Pensamiento } \\
\text { político } \\
\text { - Construir sociedad }\end{array}$ \\
\hline & $\begin{array}{l}\text { Profesor } \\
\text { Privada }\end{array}$ & I.E. & $\begin{array}{l}\text { Fortalece bases, les ayuda a reflexionar sobre creen- } \\
\text { cias o posiciones frente a situaciones. Les permite } \\
\text { abrirse al mundo; comparar y analizar }\end{array}$ & $\begin{array}{l}\text { - La reflexión y el } \\
\text { análisis } \\
\text { - Abrirse al mundo }\end{array}$ \\
\hline
\end{tabular}

Se destaca en los estudiantes la apropiación conceptual y práctica del ser político: en la institución pública existe la tendencia de comprender lo político como el ejercicio de trabajar por el bien de todos, desde el rol que se desempeñe en el contexto educativo como "estratega que sabe articular coherentemente lo público y lo privado" (Arias, \& Villota, 2007, p.47). En la institución privada, los jóvenes develan la concepción de política más desde el respeto por el otro y por las diferencias.

Los estudiantes que participan en la producción de los medios escolares comprenden 
el ser político como la manera de hacer el bien, construir sociedad de una manera intersubjetiva que permite a los estudiantes "conocer y pensar críticamente $[\ldots]$ para expresar sus emociones y sentimientos, para involucrarse en el destino de los otros" (Alvarado, Patiño, \& Loaiza, 2012, p. 859). El docente de la institución pública y el comunicador social de la privada, coinciden con la postura de los estudiantes de ambos colegios: consideran que el ser político se vive cotidianamente, desde la forma en que se comparte con los demás hasta la compleja tarea de construir sociedad y que la formación política es un asunto que emerge desde el pensamiento: principio para la construcción del ser político como sujeto que se sitúa "en el centro del mundo, tanto para conocer como para actuar" (Morín, 2006, p. 91). Por lo anterior se deduce: el medio escolar, al estar inserto en la escuela, sirve de escenario para hacer lectura crítica del mundo que viven $y$ comunicar sus propias ideas; así se desarrolla un sujeto político con capacidad de palabra.

\subsection{Bucaramanga}

Institución Educativa Pública (I.E. Pública): fundada en 1976, tiene una cobertura de 1500 estudiantes para todos los niveles de la educación básica primaria y secundaria. Tienen una emisora escolar con emisiones diarias; participan 16 estudiantes y dos profesores en el colectivo de productores.

Institución Educativa Privada (I.E. Privada): fundada en 1891, colegio administrado por una comunidad de religiosas católicas que también ofrece todos los grados de formación básica, desde el prescolar hasta el bachillerato. Tienen un programa de televisión con emisiones quincenales y una trayectoria de 26 años. Es coordinada por tres docentes con el apoyo de doce estudiantes.

Tabla 5. Resultados entrevistas estudiantes y profesores Bucaramanga sobre el medio escolar

\begin{tabular}{|c|c|c|c|}
\hline Pregunta & Actor & Concepto & Idea \\
\hline \multirow{4}{*}{$\begin{array}{l}\text { ¿Qué es un } \\
\text { medio escolar? }\end{array}$} & $\begin{array}{l}\text { Estudiante I.E. } \\
\text { Pública }\end{array}$ & $\begin{array}{l}\text { Es un medio en donde participan los estudiantes } \\
\text { con la orientación de los profesores para expre- } \\
\text { sarse y hablar con el lenguaje de los jóvenes. }\end{array}$ & $\begin{array}{l}\text { Espacio de participación } \\
\text { y expresión } \\
\text { - Lenguaje y cosmovisión } \\
\text { de los jóvenes }\end{array}$ \\
\hline & $\begin{array}{l}\text { Estudiante I.E. } \\
\text { Privada }\end{array}$ & Espacio para representar los valores del Colegio. & $\begin{array}{l}\text { - Medio para informar } \\
\text { - Espacio para fortalecer la } \\
\text { identidad institucional }\end{array}$ \\
\hline & $\begin{array}{l}\text { Profesor } \\
\text { I.E. Pública }\end{array}$ & $\begin{array}{l}\text { Medio efectivo para fortalecer la comunicación in- } \\
\text { terna y la relación entre docentes y estudiantes. }\end{array}$ & $\begin{array}{l}\text { - Medio de comunicación } \\
\text { - Espacio de expresión de } \\
\text { los estudiantes }\end{array}$ \\
\hline & $\begin{array}{l}\text { Profesor } \\
\text { I.E. Privada }\end{array}$ & $\begin{array}{l}\text { Canal que ofrecen algunos colegios para motivar } \\
\text { a los estudiantes en el interés de comunicar. }\end{array}$ & $\begin{array}{l}\text { - Canal de comunicación } \\
\text { Espacio para la moti- } \\
\text { vación y el sentido de } \\
\text { pertenencia institucional }\end{array}$ \\
\hline
\end{tabular}

En la I.E. privada el medio escolar se asume como un canal de comunicación institucional, validado con la participación de estudiantes y profesores; en la I.E. pública este se reconoce como un espacio autónomo, que promueve la opinión y expresión de los estudiantes, desde sus imaginarios y cosmovisiones.

siguiente:
Sobre el sujeto político, indican lo 
Tabla 6. Resultados entrevistas estudiantes y profesores Bucaramanga sobre el sujeto político

\begin{tabular}{|c|c|c|c|}
\hline Pregunta & Actor & Concepto & Idea \\
\hline \multirow{2}{*}{$\begin{array}{l}\text { ¿Usted se con- } \\
\text { sidera un sujeto } \\
\text { político? }\end{array}$} & $\begin{array}{l}\text { Estudiante } \\
\text { I.E. Pública }\end{array}$ & $\begin{array}{l}\text { El sujeto político es un buen ciudadano. Aquél que } \\
\text { cumple y respeta las leyes. }\end{array}$ & $\begin{array}{l}\text { - Respeta las normas } \\
\text { - Respeta las opiniones de } \\
\text { los otros }\end{array}$ \\
\hline & $\begin{array}{l}\text { Estudiante } \\
\text { I.E. Privada }\end{array}$ & $\begin{array}{l}\text { Sí, en tanto busco siempre presentar la verdad y res- } \\
\text { petar las opiniones de los demás. }\end{array}$ & $\begin{array}{l}\text { - Verdad } \\
\text { - Pluralidad }\end{array}$ \\
\hline \multirow{2}{*}{$\begin{array}{l}\text { ¿De qué mane- } \\
\text { ra los conteni- } \\
\text { dos publicados } \\
\text { en el medio } \\
\text { escolar aportan } \\
\text { a la formación } \\
\text { política de la } \\
\text { comunidad } \\
\text { educativa? }\end{array}$} & $\begin{array}{l}\text { Profesor } \\
\text { I.E. Pública }\end{array}$ & $\begin{array}{l}\text { La emisora les ayuda a hacer una lectura crítica y } \\
\text { comprensiva de la realidad y en ese sentido se cons- } \\
\text { tituye en un espacio para la formación política de los } \\
\text { estudiantes. }\end{array}$ & $\begin{array}{l}\text { - Lectura crítica } \\
\text { - Formación ideológica y } \\
\text { política }\end{array}$ \\
\hline & $\begin{array}{l}\text { Profesor } \\
\text { I.E. Privada }\end{array}$ & $\begin{array}{l}\text { Fortalece aspectos como el liderazgo y la autonomía } \\
\text { y hace una apuesta al tema de la cátedra de la paz. }\end{array}$ & $\begin{array}{l}\text { Se abordan temas rela- } \\
\text { cionados con ciudadanía, } \\
\text { deberes y derechos }\end{array}$ \\
\hline
\end{tabular}

Considerar el medio escolar como un espacio de formación del sujeto político, es la apuesta ambas instituciones. Por eso, los docentes reconocen que la participación de los estudiantes en los medios escolares fortalece aspectos como la lectura crítica de la realidad, el liderazgo y la autonomía, aspectos claves en la constitución del sujeto político, los cuales emergen en el proceso de producción de los contenidos comunicativos. De esta manera, los hallazgos permitieron identificar la presencia de lo que Pérez caracterizó como esa nueva escuela paralela que son los medios (2007, p. 7), una escuela que posibilita el desarrollo de capacidades propias del sujeto político.

\section{Conclusiones}

El proceso de producción del medio escolar favorece la formación de los estudiantes como sujetos políticos, cuando brinda la capacidad de lectura crítica de sus contextos educativos y sociales, de producir relatos conducentes a generar diálogos en la comunidad educativa y en el entorno que rodea la escuela: "dialogar es descubrir en la trama de nuestro propio ser la presencia de los lazos sociales que nos sostienen" (Martín Barbero, 2002, p. 35).

Los medios escolares ofrecen la posibilidad de conectar a los estudiantes con sus reali- dades, para ser narradas y ejercer el derecho a la comunicación, base fundamental del sujeto político; permite el desarrollo de una consciencia crítica, conocer unas normas, guiarse por unos criterios éticos que superen la negación de la palabra o el miedo a expresar las ideas. Cuando el proyecto educativo de la escuela reconoce sus potencialidades comunicativas, se consolida al medio escolar como "espacio de comprensión y, por lo tanto, se convierte en puente de estimulación del pensamiento" (Pallarès, 2014, p. 212).

Esto lleva a considerar que el medio escolar es espacio de encuentro con el otro como diferente y escenario de acuerdos colectivos, reconocimiento del disenso en los que se privilegia la pluralidad, donde se favorece la emergencia de "sujetos pensantes y hablantes" (Rojas, \& Arboleda, p. 14) sobre todo por su capacidad de comunicar y también lugar en el que aprende a reconocer al otro, a quien escucha y con quien aprende a tomar decisiones en conjunto (Rojas, \& Arboleda).

Un medio escolar entendido como espacio y proceso de producción de contenidos, con la intención de formar productores de sentido, más que reproductores (Duschatzky, Farrán, \& Aguirre, 2010) sirve de escenario para formar sujetos políticos en la escuela, esto es, estudiantes que aprendan a respetar la diferencia, a leer su 
cotidianidad, tener pensamiento crítico y relatar sus vivencias. Siguiendo a Romero (2011), los medios escolares al asumirse como espacios de intercambio simbólico y cultural, pueden potenciar a los estudiantes como productores y sujetos políticos con capacidad de palabra para relatar su mundo y aportar sus ideas para transformarlo.

\section{Nota}

1. El Grupo de Investigación en Comunicación Urbana, GICU de Medellín; el Grupo de Investigación Comunicación y Educación, COEDU de Montería y el Grupo de Investigación Comunicación, Cultura y Desarrollo de Bucaramanga, hacen parte de las Facultades de Comunicación Social-Periodismo en las ciudades colombianas donde tiene sede la Universidad Pontificia Bolivariana, UPB.

\section{Referencias bibliográficas}

Alvarado, S., Patiño, J., \& Loaiza, J. (2012). Sujetos y subjetividades políticas: El caso del movimiento juvenil Álvaro Ulcué. Revista Latinoamericana de Ciencias Sociales, Niñez y Juventud, 1(10), 855-869.

Angrosino, M. (2012). Etnografía y observación participante en investigación cualitativa. Madrid: Morata.

Arias, G., \& Villota, F. (2007). De la política del sujeto al sujeto político. Revista Ánfora, 14(23). Universidad Autónoma de Manizales. Facultad de Estudios Sociales y Empresariales.

Aparici, R., \& García, D. (2017). Comunicar y educar en el mundo que viene. Barcelona: Editorial Gedisa.

Bacher, S. (2009). Tatuados por los medios. Dilemas de la educación en la era digital. Buenos Aires: Paidós.

Barbas, A. (2012). Educomunicación: desarrollo, enfoques y desafíos en un mundo interconectado. Foro de Educación, 10(14). 166-167. (http://bit.ly/2HnO4Hp). (2017-05-12).

Ceballos, J., \& Marín, B. (2017). Los medios escolares conversan para vivir la ciudad. Revista Latinoamericana de Ciencias de la Comunicación, Alaic, 14(26), 52-61. (http:// bit.ly/2Cz4Yx9). (2018-09-22).
Duschatzky, S. Farrán, G., \& Aguirre, E. (2010). Escuelas en escena. Una experiencia de pensamiento colectivo. Buenos Aires: Paidós.

Fernández,L.(2015).Tecnologíasymedios de comunicación como alternativas para la construcción del sujeto político. Revista deInvestigaciones 15(25), 82-99. Universidad Católica de Manizales (http://dx.doi.org/10.22383/ri.v15i1.35)

Freinet, C. (1977). El diario escolar. Barcelona: Editorial Laia.

Freinet, E. (1983). Nacimiento de una pedagogía popular. Historia de una escuela moderna. Barcelona: Editorial Laia.

Freire, P. (1985). Pedagogía del oprimido. (33a. ed.) México: Siglo XXI Editores.

Freire, P. (2008). El grito manso. Buenos Aires: Siglo XXI Editores.

Guber, R. (2001). La etnografía. Método, campo y reflexividad. Bogotá: Norma.

Henao, O. (2012). Educación 'en' y 'para' la democracia. Medellín: Alcaldía de Medellín.

Huergo, J. (2001). Comunicación/educación. Ámbitos, prácticas y perspectivas. La Plata: Universidad Nacional de La Plata.

Huergo, J. y Fernández, M. (2000). Cultura escolar, cultura mediática/intersecciones. Bogotá: Universidad Pedagógica Nacional.

Kaplún (1998). Una Pedagogía de la Comunicación. Madrid: Ediciones la Torre

Kaplún, M. (2010). Una pedagogía de la comunicación. En R. Aparici (Coord.), Educomunicación: más allá del 2.0 (pp. 41-61). Barcelona: Gedisa.

Kriger, M. (2010). Jóvenes de escarapelas tomar Escolaridad, comprensión histórica y formación política en la Argentina contemporánea. La Plata: Editorial Universidad Nacional de La Plata.

Martín Barbero, J. (1998). De los medios a las mediaciones. Comunicación, cultura, hegemonía. Bogotá: Convenio Andrés Bello.

Martín Barbero, J. (2002). La educación desde la comunicación. Bogotá: Norma

Martínez, J. (2014). Dispositivos de producción de subjetividad: la interacción entre educación y comunicación. En comunicación educación un campo de resistencias. En Z. Bautista, Comunicación Educación un campo de resistencias. Bogotá: Corporación Universitaria Minuto de Dios. 
Morín, E. (2006). La naturaleza de la naturaleza. Madrid: Cátedra Teorema.

Mujica, C. (2001). Construyendo comunicación: el caso de niños y niñas de una escuela popular. En D. Crovi Druetta, Comunicación y Educación, la perspectiva latinoamericana (pp. 281-310). México: ILCE.

Nussbaum, M. (2014). Emociones políticas. ¿Por qué el amor es importante para la justicia? Bogotá: Paidós (Editorial Planeta).

Pallarès, M. (2014). Los medios de comunicación y tecnológicos como ejes de canalización y gestión del conocimiento. Educar, 50(1), 207-229.

Perceval, J., \& Tejedor, S. (2008). Oral-gestual, escritura, audio, audiovisual y idigital? Los cinco grados de la comunicación en educación. Comunicar, XV(30), 155-163.

Pérez, A. (1998). La cultura escolar en la sociedad neoliberal. Madrid: Ediciones Morata.

Pérez, J.M. (2007). Comunicación y Educación. Cuestiones clave. Madrid: Mentor Media Education.

Reguillo, R. (1998). De la pasión metodológica o de la (paradójica) posibilidad de la investigación. En R. Mejía, y S. Sandoval (Coord.), Tras las vetas de la investigación cualitativa. Perspectivas y acercamientos desde las prácticas (pp. 17-34). Jalisco: Iteso.

Reynaga, S. (1998). Perspectivas cualitativas de investigación en el ámbito educativo. La etnografía y la historia de vida. En R. Mejía, y S. Sandoval (Coord.), Tras las vetas de la investigación cualitativa. Perspectivas y acercamientos desde las prácticas (pp. 123-154). Jalisco: Iteso.
Rodríguez, J. (2004). Medios y tecnologías de la información y la comunicación: una caracterización de las prácticas en instituciones escolares de Bogotá. Revista Colombiana de Educación, (46), 186-218.

Rojas, A., \& Arboleda, R. (2014). La construcción del sujeto político en la escuela. Revista Aletheia, 6 (1). 124-139. (http://dx.doi.org/10.11600/2 1450366.6.1aletheia.124.139)

Romero, M. (2011). Nuevos paisajes para los medios escolares en los terrenos de la sociedad de la información. Hologramatica 14(2), 45-66 (http://www.cienciared.com.ar/ra/ usr/3/1098/hologramatica_n14_v2pp45_66. pdfhttp://bit.ly/2FFYpNe) (2018-08-15).

Ruiz Silva, A., \& Prada Londoño, M. (2012). La formación de la subjetividad política. Propuestas y recursos para el aula. Buenos Aires: Paidós.

Ruiz, A. (2008) El diálogo que somos. Ética discursiva y educación. Bogotá: Civitas Magisterio.

Saintout (2003). La ruptura. Un campo en movimiento. En F. Saintout, Abrir la comunicación. Tradición y movimiento en el campo académico. La Plata: Editorial Universidad Nacional de La Plata.

Valderrama, C. (2007). Ciudadanía y comunicación. Saberes, opiniones y haceres escolares. Bogotá: Siglo del Hombre Editores. Universidad Central, Iesco.

Valderrama, C. (2010). Ciudadanía y formación ciudadana en la sociedad de la información. Una aproximación desde la Comunicacióneducación. En R. Aparici, Educomunicación: más allá del 2.0. (pp. 281-305). Barcelona: Editorial Gedisa. 